Research Article

\title{
Effectiveness of Exercise Programs on Patients with Dementia: A Systematic Review and Meta-Analysis of Randomized Controlled Trials
}

\author{
Xudong Li, ${ }^{1}$ Rui Guo, ${ }^{2}$ Zhenhong Wei, ${ }^{2}$ Jing Jia, ${ }^{2}$ and Chaojun Wei ${ }^{2}{ }^{2}$ \\ ${ }^{1}$ Department of Physical Education, Lanzhou University, Lanzhou, China \\ ${ }^{2}$ The Institute of Clinical Research and Translational Medicine, Gansu Provincial Hospital, Lanzhou, China \\ Correspondence should be addressed to Chaojun Wei; weichaojun0312@126.com
}

Received 17 June 2019; Revised 13 September 2019; Accepted 16 October 2019; Published 22 November 2019

Academic Editor: Stavros Baloyannis

Copyright (c) 2019 Xudong Li et al. This is an open access article distributed under the Creative Commons Attribution License, which permits unrestricted use, distribution, and reproduction in any medium, provided the original work is properly cited.

Exercise programs have been introduced to improve cognitive function, whereas studies showed inconsistent results regarding the effectiveness of exercise programs on patients with dementia. This study aimed to summarize randomized controlled trials (RCTs) to assess the effect of exercise programs on cognition, activities of daily living (ADL), and depression in elderly with dementia. We systematically screened PubMed, Embase, and the Cochrane library for relevant studies throughout November 21, 2018. The pooled standardized mean differences (SMDs) with 95\% confidence intervals (CIs) were employed to calculate cognition, ADL, and depression by using random-effects model. A total of 20 RCTs with 2,051 dementia patients were included in final quantitative meta-analysis. There were no significant differences between exercise programs and control regarding cognition (SMD: 0.44; 95\% CI: $-0.21-1.09 ; P=0.183$ ), ADL (SMD: 0.50; 95\% CI: $-0.03-1.02 ; P=0.066$ ), and depression (SMD: $-0.43 ; 95 \%$ CI: $-0.90-0.05$; $P=0.077)$. Sensitivity analysis results indicated that exercise programs might play an important role in cognition and ADL, whereas the depression level was unaltered by the exclusion of any particular study. Subgroup analyses indicated that exercise programs were associated with increased cognitive levels if the mean age of patients was $<80.0$ years when compared with usual care and studies with low quality. Moreover, the ADL level was significantly increased in patients receiving exercise programs versus usual care. These results suggested that exercise programs might play an important role in cognition and ADL in patients with dementia. These results required further verification by large-scale RCTs, especially for depression outcomes.

\section{Introduction}

Dementia is a major neurological disorder that causes disability and dependency among individuals, and so it has become a significant global problem. The prevalence of dementia among the elderly ( $\geq 60$ years) people is $4.86 \%$ worldwide [1]. The incidence of dementia is accompanied with the ageing process of the individuals, and its prevalence is increasing worldwide [2]. The characteristic of dementia involves a progressive declination in cognition, which in turn is associated with the loss of social and occupational functions [3]. Moreover, patients with dementia have poor balance and gait [4], and gait might be a surrogate marker of cognitive impairment and decline, which could affect the dependence of activities of daily living (ADL) [5].
Furthermore, there is convincing evidence that demonstrated that both notion and depression in early life are associated with increased risk of dementia in later life, while depression in later life could be regarded as a prodrome to dementia [6]. Although pharmacological treatments have been employed for improving cognitive function and ADL, various side effects and no disease modifications were observed in patients with dementia $[7,8]$. Therefore, effective strategies should be explored for patients with dementia.

According to a previous study, exercise assists in gradually slowing down the progression of dementia. The potential reasons for this could be the fact that regular exercise has direct effects on the brain cortex, neuromuscular and cardiovascular functioning, immune system, arteriosclerosis in the brain, mood, and depression states [9]. 
Furthermore, regular exercises could decrease neuropathological burden and increase hippocampal neurogenesis $[10,11]$. A previous systematic review was conducted on dementia patients and pointed out that regular exercise has no significant effect on cognition and depression, while it provides a beneficial effect on ADL [12]. However, this study evaluated the results of cognition, ADL, and depression based on the data after intervention, but the mean changes of these indexes were not calculated. Moreover, whether the treatment effects of exercise are differing according to patients' characteristics was not illustrated. Therefore, this current meta-analysis was conducted based on randomized controlled trials (RCTs) to determine the treatment effects of exercise programs on cognition, ADL, and depression in patients with dementia.

\section{Materials and Methods}

2.1. Data Sources, Search Strategy, and Selection Criteria. This study was conducted and reported according to the guidelines of Preferred Reporting Items for Systematic Reviews and Meta-Analysis Statement (PRISMA) [13]. The electronic databases of PubMed, Embase, and the Cochrane library were systematically searched for RCT studies published regarding the investigation of treatment effects of exercise programs in patients with dementia from their inception up to November 21, 2018. The following search terms as medical subjecting heading and free words were used: (exercise or training) and (dementia or Alzheimer's disease) and "English." The detailed information regarding the search strategy was presented in Supplemental 1. The reference list of the retrieved studies was also reviewed to identify any new eligible study.

Two authors independently conducted literature search and study selection, and any inconsistencies between them were resolved by discussion with each other. The inclusion criteria of this study are as follows: (1) patients: patients without any restriction to age were diagnosed with dementia according to the diagnosis criteria in individual trial; (2) intervention: patients received regular exercise programs, and the details of exercise programs have been listed in Table 1; (3) control: control is patients with usual care and without regular exercise; (4) outcomes: the study should report at least 1 of the following outcomes: cognition, ADL, and depression; and (5) study design: study design is RCT design.

2.2. Data Collection and Quality Assessment. Data collection and quality assessment were carried out by 2 authors, and disagreement was adjudicated by an additional author by reading the full text of the article. The collected items included study, publication year, country, sample size, mean age, intervention, control, treatment duration, diagnostic criteria, and reported outcomes. The quality of included studies was evaluated by using the revised Jadad scale that is based on random sequence generation, allocation concealment, blinding, blinding of outcome assessment, incomplete outcome data, selective reporting, and other biases [34]. The "score system" for RCTs ranged from 0 to 7, where studies with score of 5 or more are regarded as high-quality studies.

2.3. Statistical Analysis. The treatment effects of exercise programs versus control on cognition, ADL, and depression based on mean, standard deviation, and sample size in each group in individual trial were calculated. The pooled standardized mean differences (SMDs) with 95\% confidence intervals (CIs) were calculated for cognition, ADL, and depression using random-effects model [35, 36]. Heterogeneity was evaluated using $I$-square and $Q$ statistic, and $P<0.10$ was considered as significant heterogeneity $[37,38]$. The stability of pooled results for investigating the outcomes was calculated by using sensitivity analyses [39]. Stratified analyses for cognition, ADL, and depression were performed based on publication year, country, sample size, mean age, control, treatment duration, and study quality. Univariable metaregression was conducted to evaluate the differences between subgroups [40]. The funnel plots, Egger et al. [41], and Begg and Mazumdar [42] tests were employed for evaluating the publication bias. The inspective levels for pooled results are 2 -sided, and $<0.05$ was considered to be statistically significant. All analysis was conducted using STATA software (version 10.0; Stata Corporation, College Station, TX, USA).

\section{Results}

3.1. Search of the Published Literature. The electronic searches produced 2,146 records, and manual search of the reference lists of retrieved studies identified 59 studies. One hundred and twenty records were removed due to duplicate topics, and 2,042 studies were excluded due to irrelevant topics after studying the title and abstract. The remaining 43 studies were retrieved for full-text evaluations, and 23 studies of these were excluded due to the following reasons: no sufficient data $(n=12)$, no appropriate control $(n=9)$, and studies reporting similar populations $(n=2)$. Finally, 20 RCTs were identified for quantitative analysis [14-33]. The details of study selection process are shown in Figure 1. The baseline characteristics of included studies are presented in Table 1.

3.2. Study Characteristics. A total of $20 \mathrm{RCTs}$ involving a total of 2,051 patients with dementia were included in the final analysis. The studies published between 1997 and 2018 and sample sizes ranged from 11 to 415 were included. The mean age of patients ranged from 70.5 to 87.9 years, and the treatment duration ranged from 6 weeks to 18 months. Fourteen studies were conducted in Europe, and the remaining 6 studies were conducted in USA, Brazil, Australia, Korea, and China. Eleven studies compared the exercise program with other strategies, while the remaining 9 studies compared the exercise program with usual care. The revised Jadad scale was used for quality evaluation, where 5 studies scored 6,7 studies scored 5,3 studies scored 4, 4 studies scored 3 , and the remaining 1 study scored 2 . 


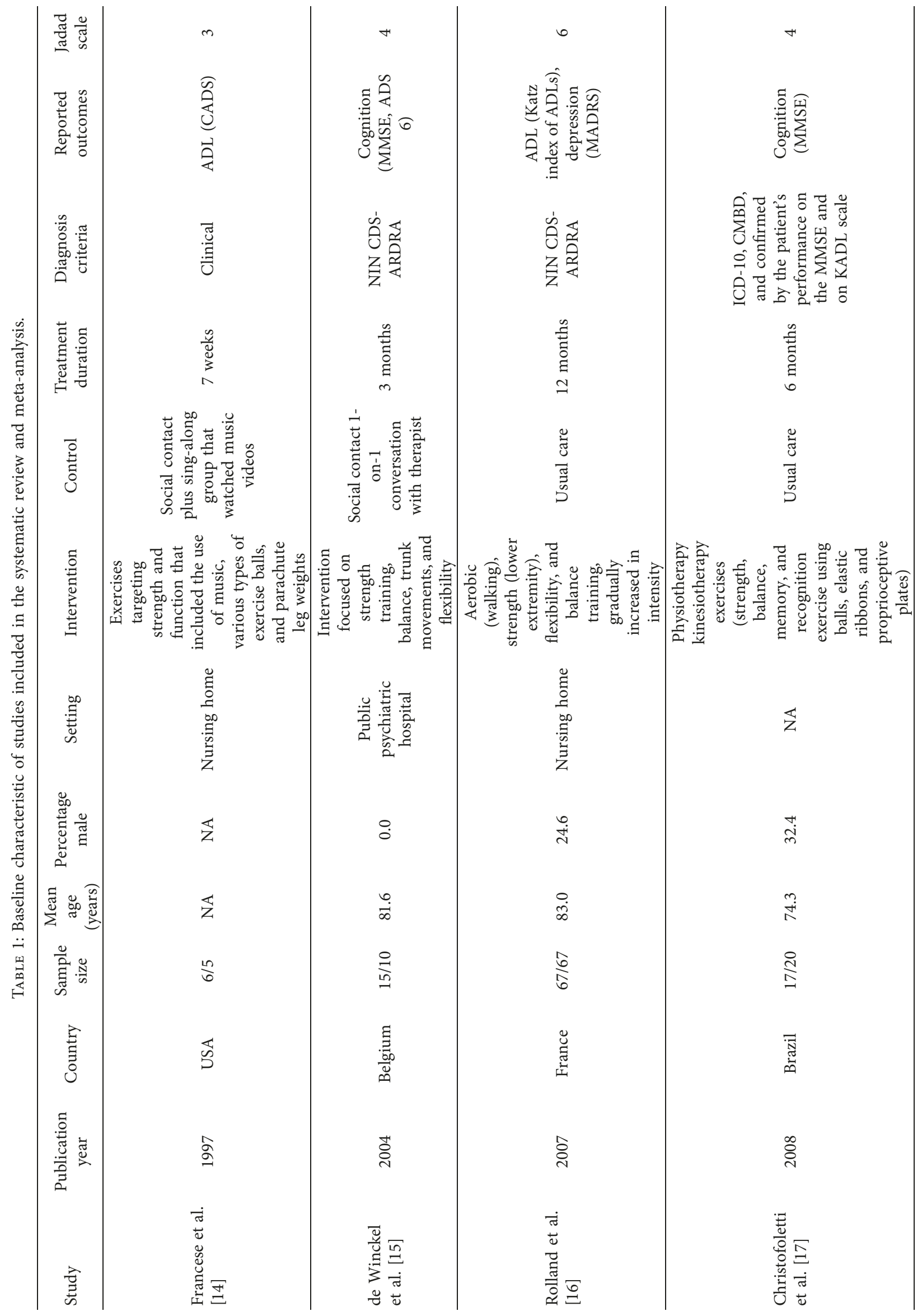




\begin{tabular}{|c|c|c|c|c|}
\hline 胥 & $r$ & in & in & in \\
\hline 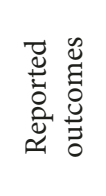 & 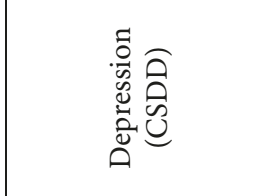 & : & 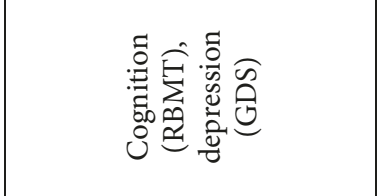 & 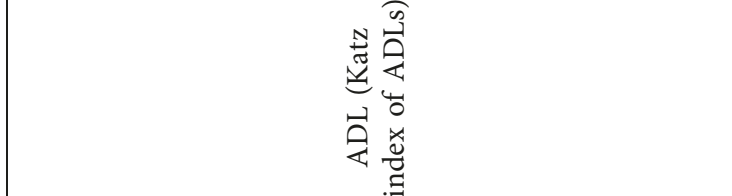 \\
\hline 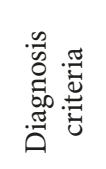 & 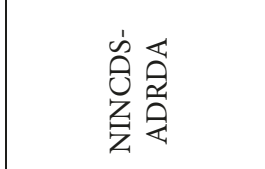 & 岛 & $\sum_{\substack{1 \\
0}}^{i}$ & 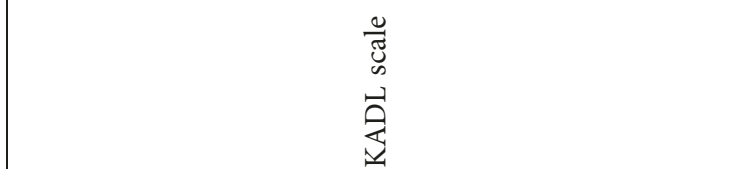 \\
\hline 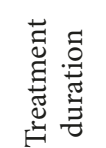 & 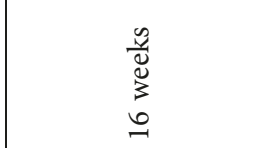 & 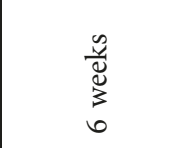 & $\begin{array}{l}\frac{n}{\tilde{e}} \\
3 \\
3\end{array}$ & 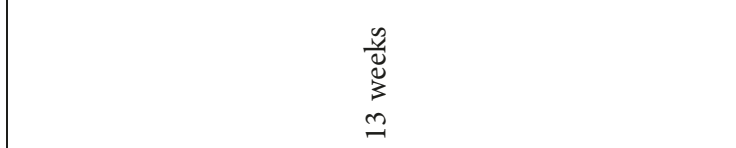 \\
\hline $\begin{array}{l}\overrightarrow{0} \\
\text { 苛 }\end{array}$ & 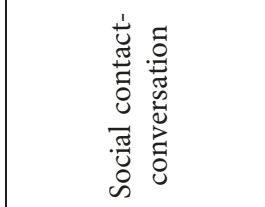 & 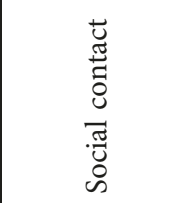 & 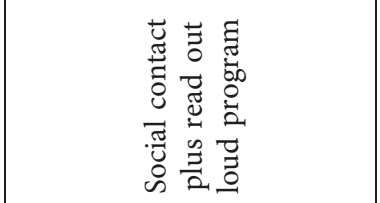 & 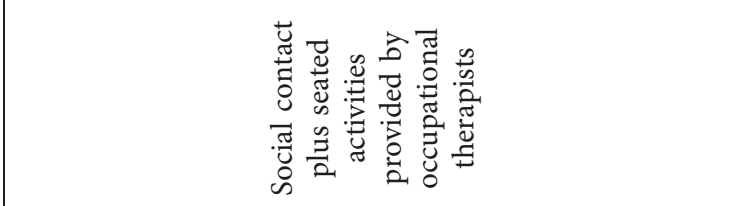 \\
\hline 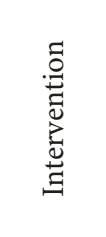 & 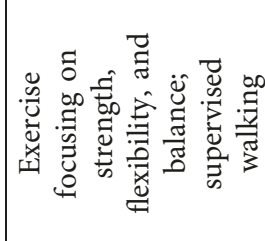 & 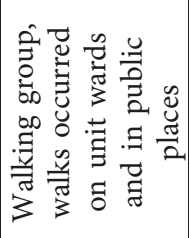 & 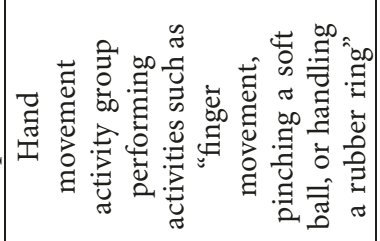 & 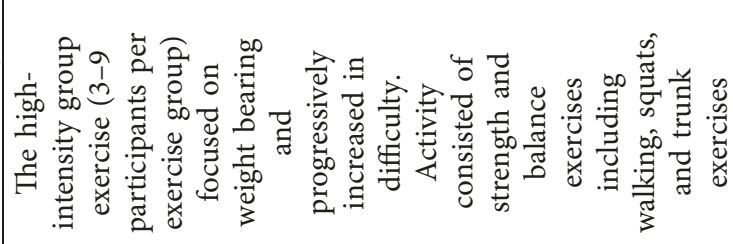 \\
\hline 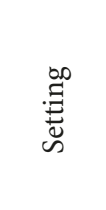 & 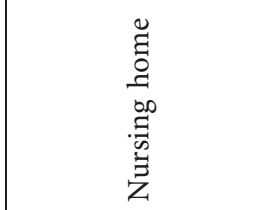 & 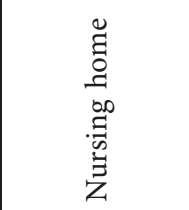 & 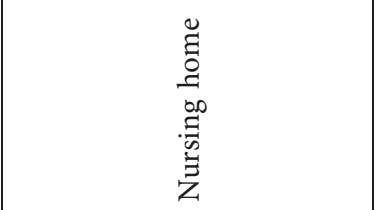 & 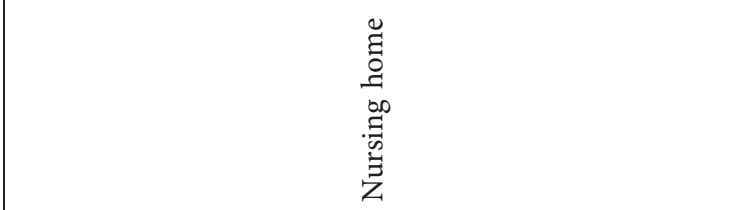 \\
\hline 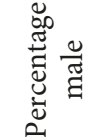 & $\stackrel{\circ}{=}$ & $\underset{\infty}{0}$ & $\overleftrightarrow{z}$ & $\underset{\text { ㄱ. }}{\stackrel{0}{0}}$ \\
\hline 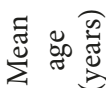 & 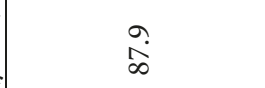 & $\underset{\infty}{\stackrel{4}{\infty}}$ & $\begin{array}{l}0 \\
+ \\
+\end{array}$ & 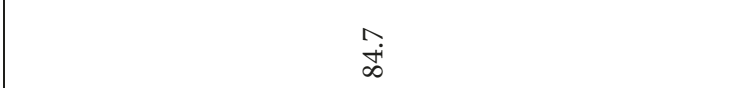 \\
\hline 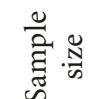 & $\underset{\sim}{\stackrel{m}{m}}$ & $\underset{\text { in }}{\stackrel{\text { In }}{n}}$ & $\frac{\vec{m}}{\partial}$ & $\sigma$ \\
\hline 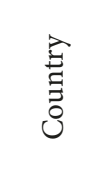 & 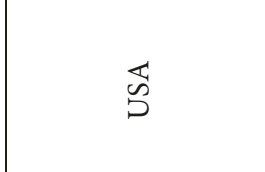 & 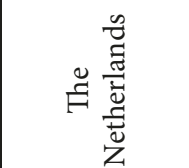 & 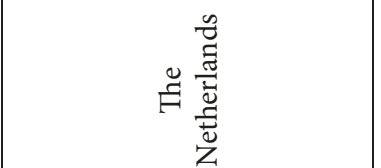 & 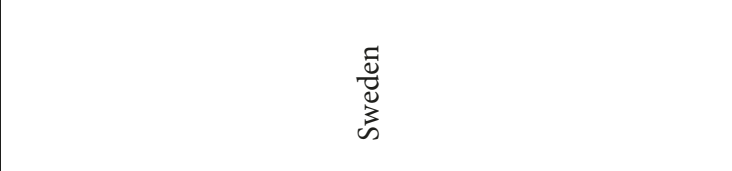 \\
\hline 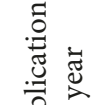 & 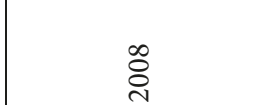 & ஓे & ஓ्रे & $\stackrel{\circ}{\stackrel{\circ}{\circ}}$ \\
\hline 蛋 & 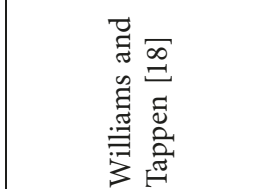 & 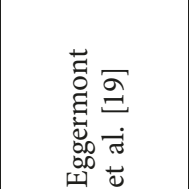 & 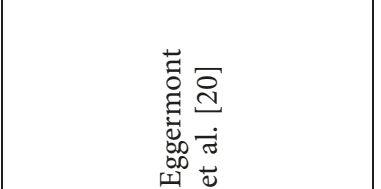 & 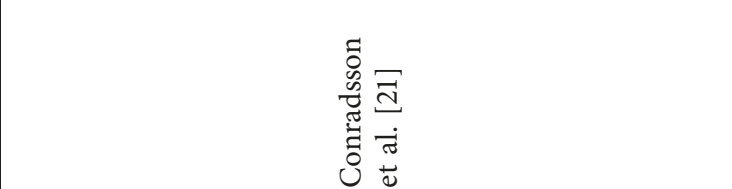 \\
\hline
\end{tabular}




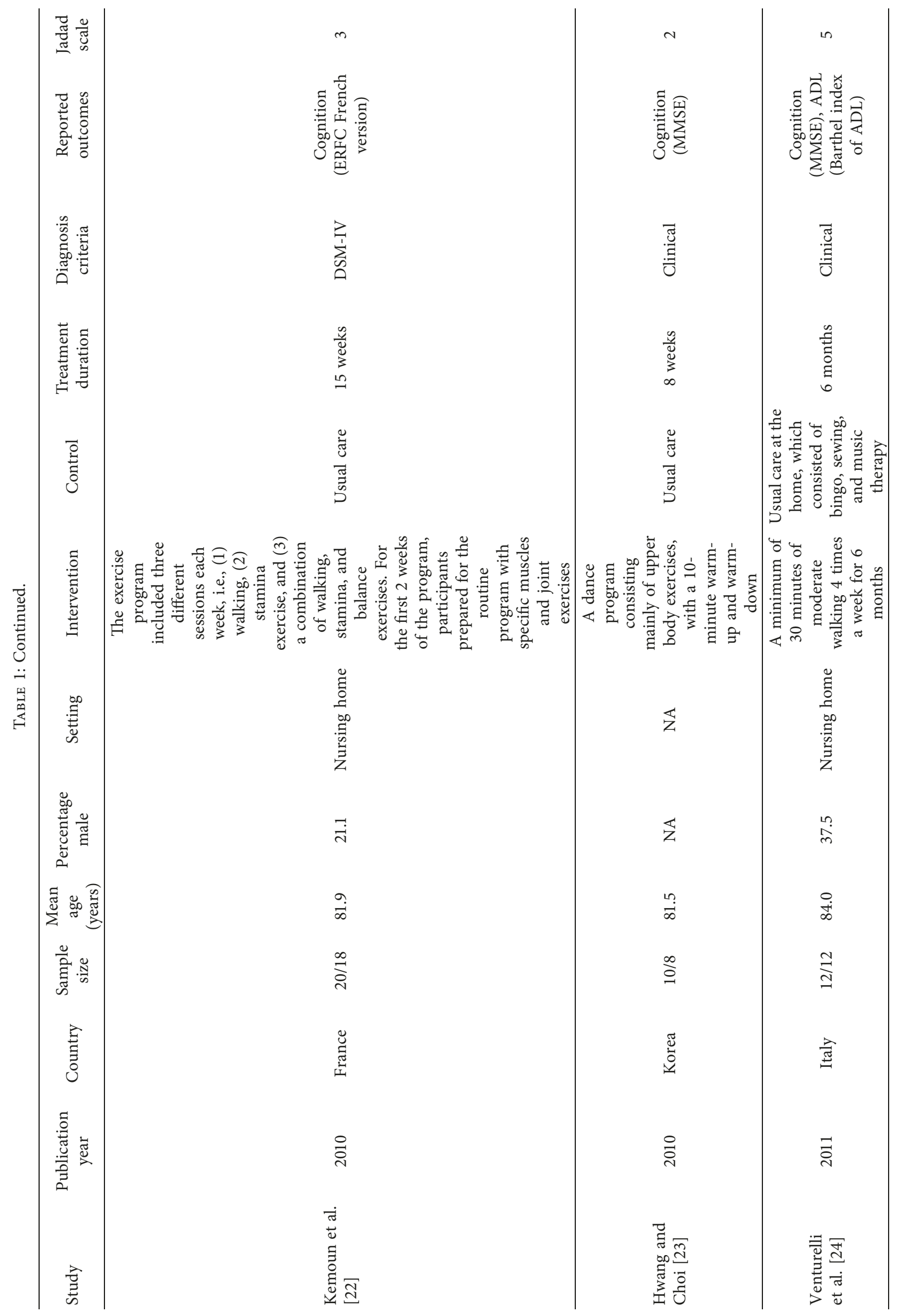




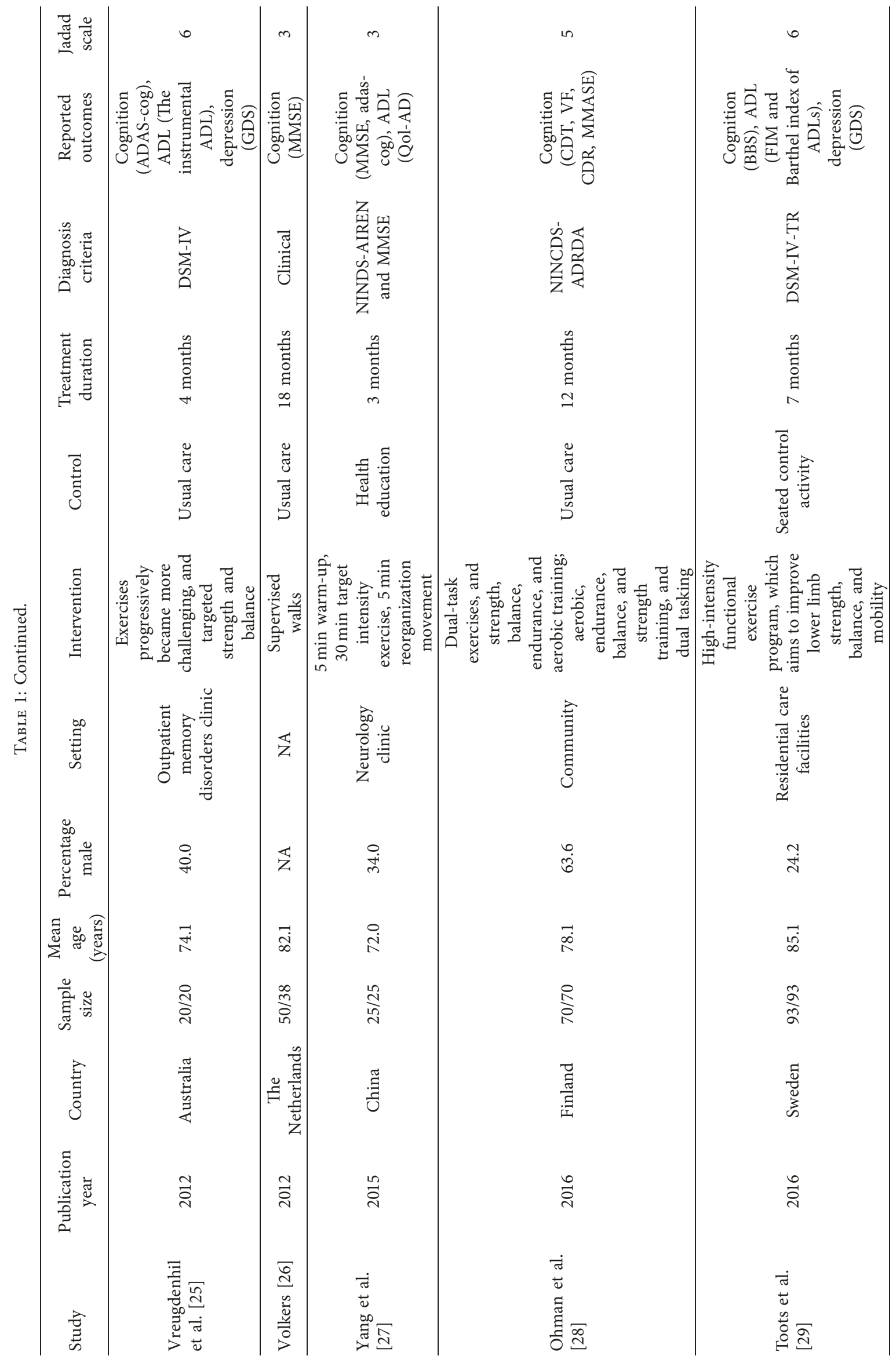




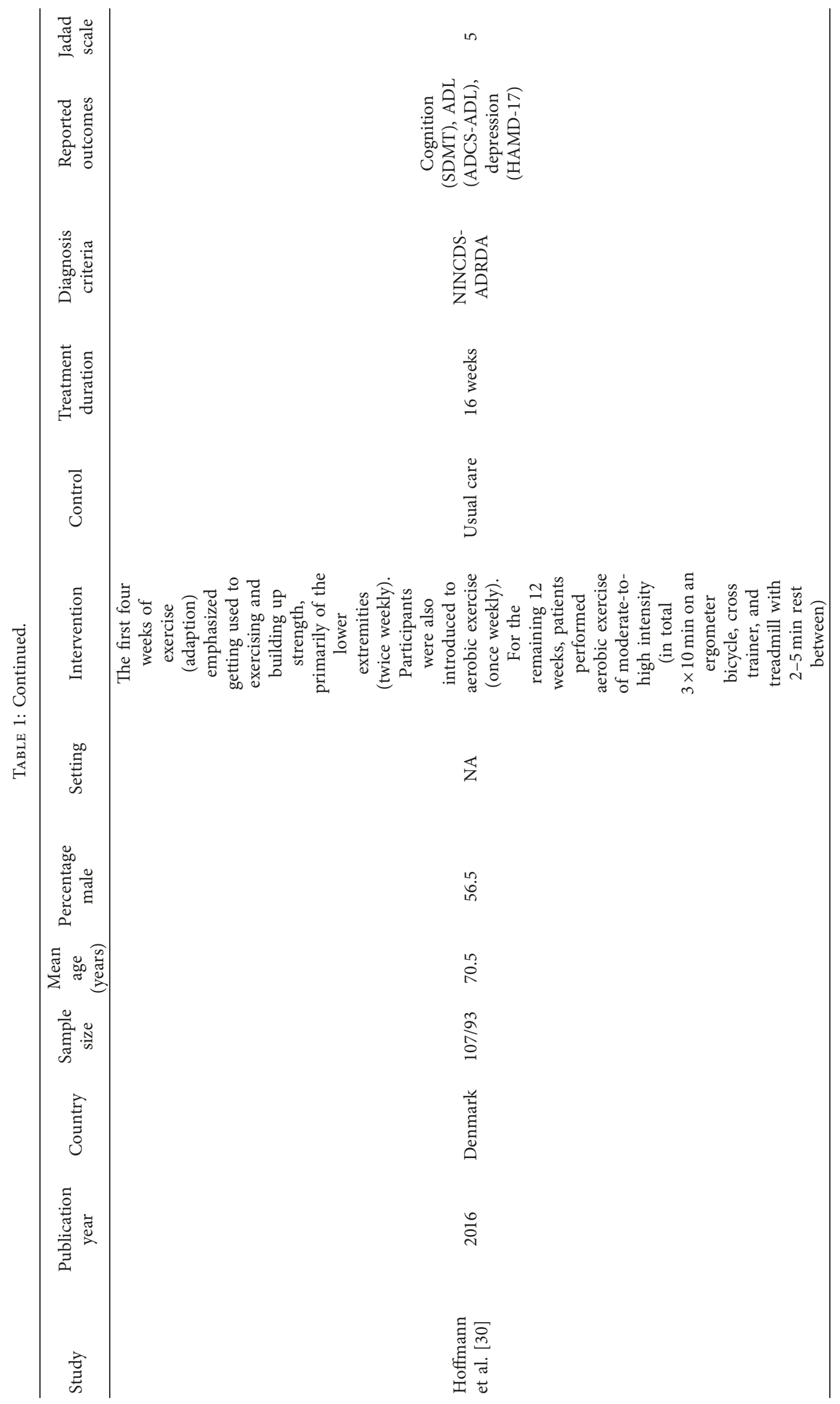




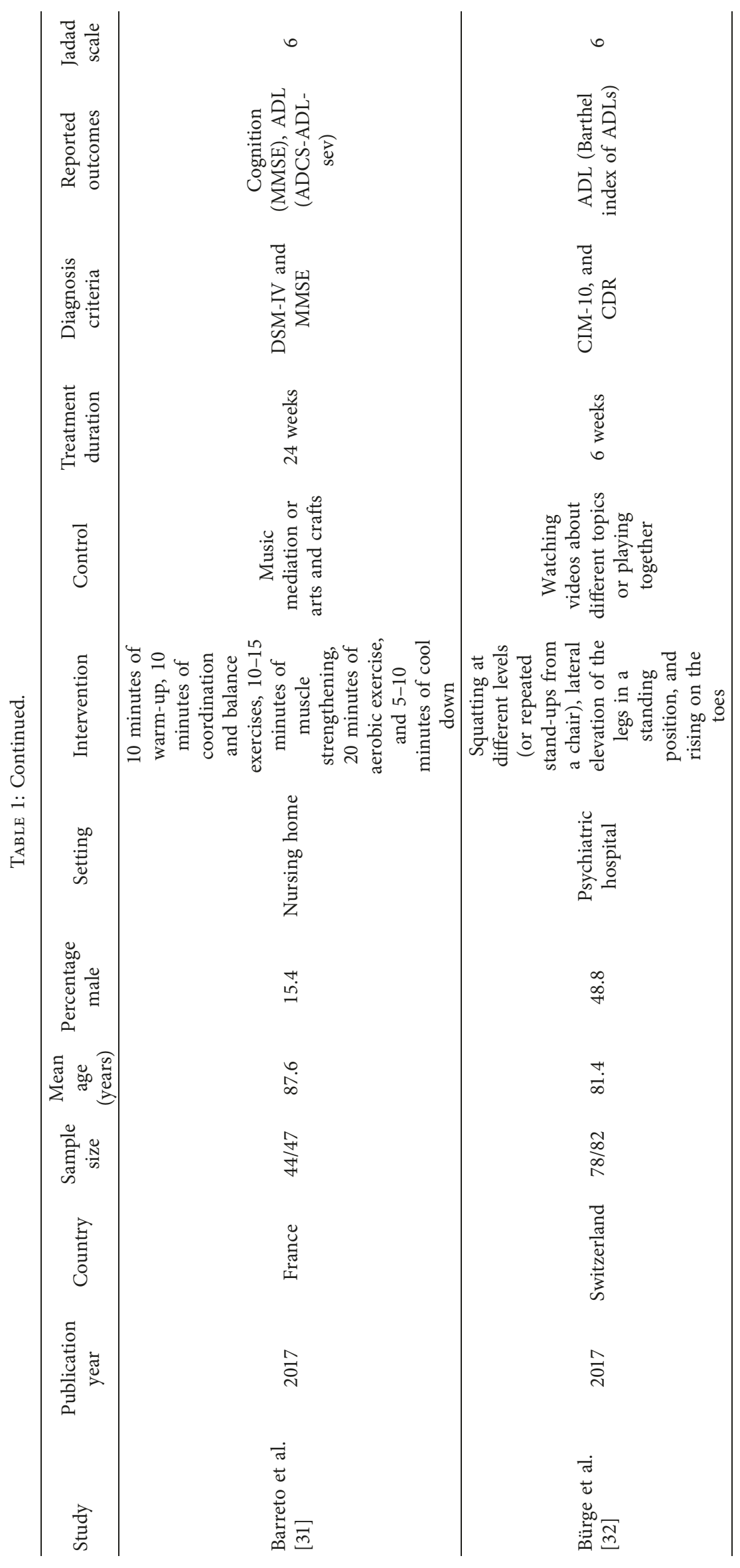




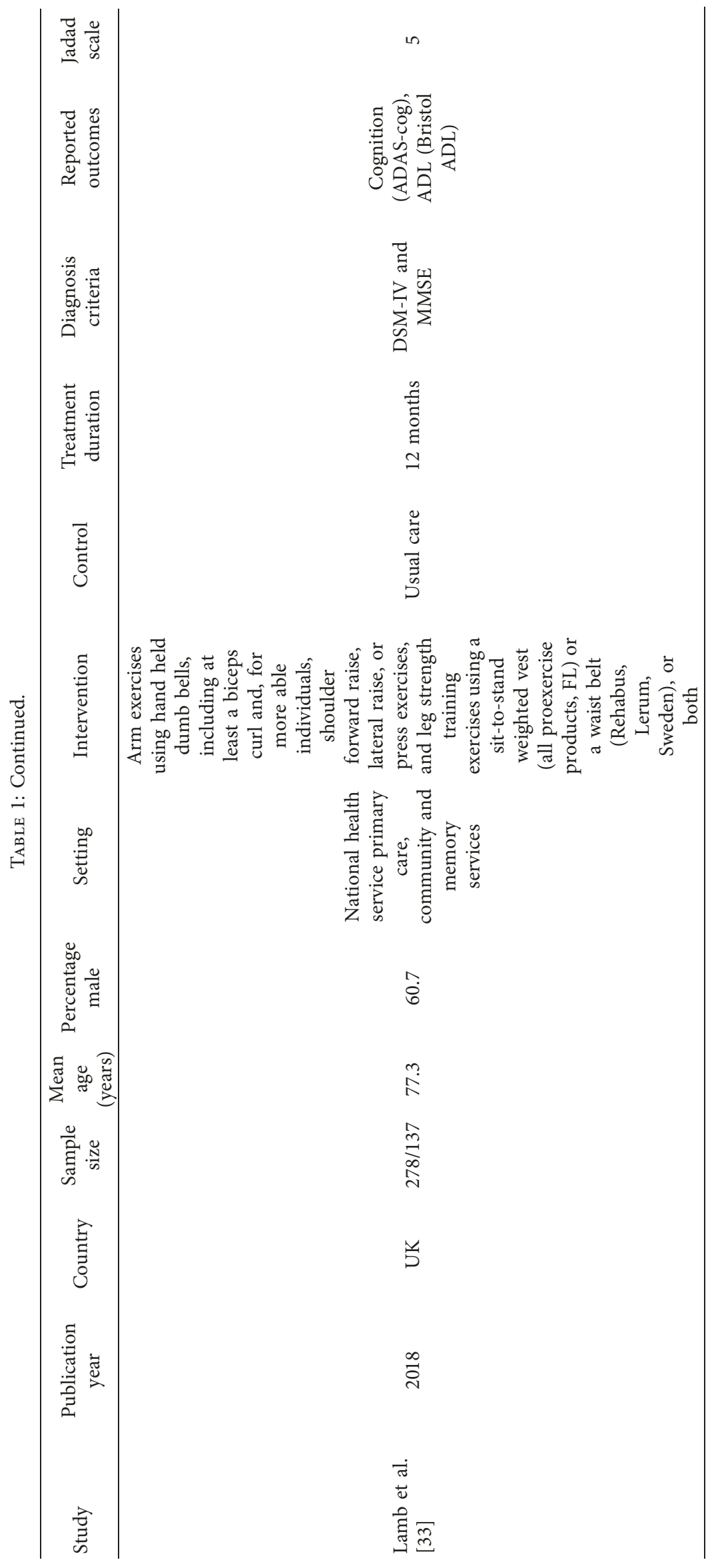




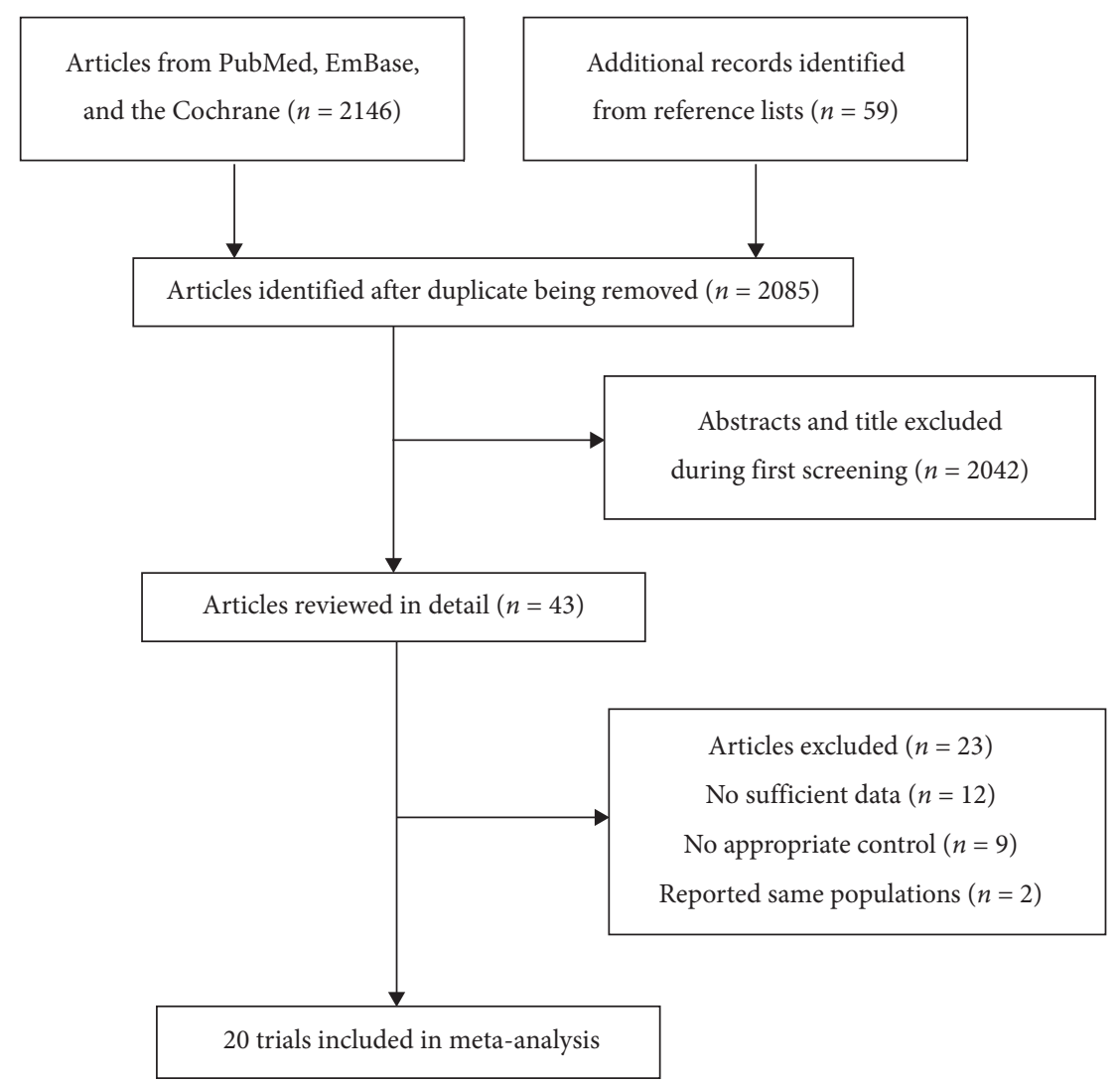

FIgURE 1: Flow diagram of literature search and trials selection process.

3.3. Cognition. Data regarding the effect of exercise program on cognition was available in 15 studies, and the pooled SMD indicated no significant differences between exercise program and control for cognition level (SMD: 0.44; 95\% CI: -0.21 to $1.09 ; P=0.183$; Figure 2$)$. Moreover, substantial heterogeneity was observed among the included studies ( $I$ square: $96.7 \% ; P<0.001)$. Sensitivity analysis indicated that exercise program had a beneficial effect on cognition after excluding the study conducted by Toots [29], and the study specified that receiving high-intensity functional exercise program aimed to improve lower limb strength, balance, and mobility (Supplemental 2). Subgroup analyses indicated that exercise program significantly improved cognition in patients with mean age of $<80.0$ years (SMD: 0.97; 95\% CI: 0.07 to $1.87 ; P=0.035$ ), compared with usual care (SMD: 1.06 ; 95\% CI: 0.35 to $1.76 ; P=0.003$ ) and pooled low-quality studies (SMD: $0.44 ; 95 \% \mathrm{CI}$ : 0.06 to $0.83 ; P=0.024$ ). No other significant differences were observed based on predefined factors (Table 2). Subgroup analysis indicated that the treatment effects of exercise program differed based on country $(P=0.001)$, mean age $(P<0.001)$, control $(P<0.001)$, and study quality $(P=0.006)$. Funnel plot did not rule out potential publication bias, and the Egger test $(P=0.355)$ showed no significant publication bias, whereas the Begg test $(P=0.048)$ showed potential publication bias (Supplemental 3).

3.4. ADL. Data regarding the effect of exercise program on ADL was available in 11 studies. We noted that exercise program has no significant effect on the levels of $\mathrm{ADL}$ when compared with control (SMD: $0.50 ; 95 \% \mathrm{CI}:-0.03$ to 1.02; $P=0.066$; Figure 3), whereas significant heterogeneity was observed ( $I$-square: $94.9 \% ; P<0.001$ ). Sensitivity analysis indicated that the conclusion was changed after excluding the trial conducted by de Souto Barreto et al. [31], which specifically compared music mediation or arts and crafts (Supplemental 2). Subgroup analysis indicated that exercise program significantly improved ADL when compared with usual care (SMD: 0.87; 95\% CI: 0.19 to 1.54 ; $P=0.012$ ), and no other significant differences were detected (Table 2). Country $(P=0.001)$, mean age $(P=0.023)$, and treatment duration $(P<0.001)$ affected the exercise programs on ADL. No evidence of publication bias was observed ( $P$ value for Egger: $0.413 ; P$ value for Begg: 0.213; Supplemental 3).

3.5. Depression. Data regarding the effect of exercise program on depression was available in 6 studies. The pooled SMD suggested that exercise programs did not yield any beneficial effects on depression level (SMD: -0.43 ; 95\% CI: -0.90 to $0.05 ; P=0.077$; Figure 4 ), and a significant heterogeneity among the included studies was detected ( $I$ square: $85.7 \% ; P<0.001$ ). Sensitivity analysis results indicated the stability of pooled conclusion after sequential exclusion of individual trial (Supplemental 2). Moreover, although the treatment effect of exercise program was affected by country $(P=0.003)$ and sample size $(P=0.022)$, no significant differences were observed between exercise 


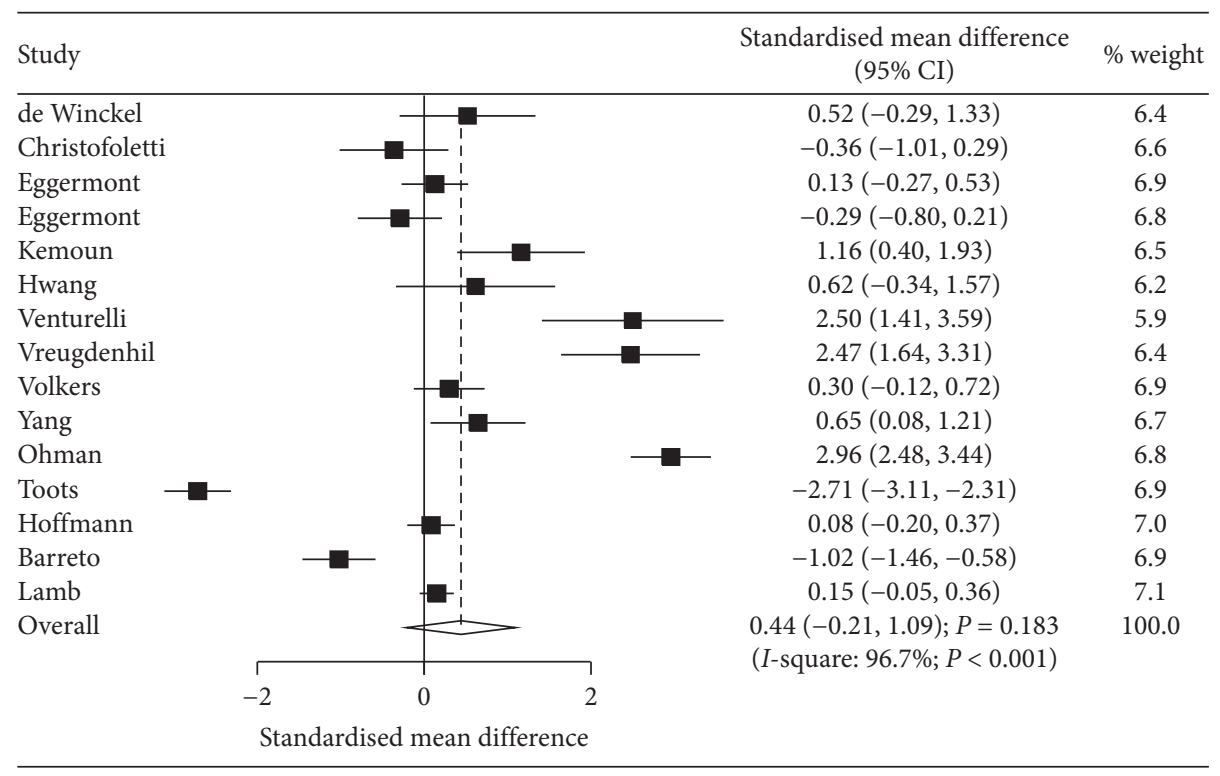

FIGURE 2: Effect of exercise programs on cognition.

programs and control for depression levels in all subsets (Table 2). There was no evidence of publication bias for depression ( $P$ value for Egger: 0.134; $P$ value for Begg: 0.260 ; Supplemental 3).

\section{Discussion}

The current study was based on 2,051 patients with dementia from 20 RCTs with broad range of characteristics. Although significant heterogeneity was observed, we noted that the dementia patients who received exercise programs did not yield additional beneficial effects on cognition, ADL, and depression. Sensitivity analysis results indicated that exercise programs might play an important role in cognition and ADL. The beneficial effects of exercise programs on cognition were mainly observed in mean age of patients $<80.0$ years when compared with usual care and pooled low-quality studies. Moreover, we also noted that exercise programs could improve ADL when compared with usual care. These results are important for patients with dementia and warranted further large-scale RCTs to verify.

According to a previous systematic review based on 13 RCTs, AD patients receiving exercise programs showed positive effects on cognitive function, and 8/13 studies reported similar results, whereas the remaining 5 studies demonstrated no significant difference between exercise programs and control regarding cognitive function [43]. However, the results of ADL and depression are not reported, and stratified analyses based on patients' characteristics are not conducted. Blankevoort et al. indicated that physical activity has beneficial effects on patients with dementia during all stages. Moreover, combination of endurance, strength, and balance interventions significantly improved gait speed, functional mobility, and balance [44]. Lee et al. based on 9 studies suggested that dementia patients receiving physical capacity were associated with improved dementia symptoms, ADL, cognitive functions, and psychological state [45]. However, several important studies were not included in this study, and the treatment effects of exercise programs might be overestimated. Liang et al. conducted a network meta-analysis based on 17 RCTs and pointed out that physical exercise and computerized cognitive training play a beneficial role in cognition and neuropsychiatric symptoms in elderly patients with AD or mild cognitive impairment [46]. Due to these controversies, the current meta-analysis was conducted to demonstrate the treatment effects of exercise program versus control on cognition, ADL, and depression in patients with dementia.

Although the pooled SMD indicated no significant difference between exercise programs and control in cognition, this result was not stable and a beneficial effect might be observed. Five of the included studies reported similar positive results, whereas 2 trials reported opposite conclusion [29, 31]. Toots et al. indicated that high-intensity functional exercise program showed significant declination in ADL and improved balance in patients with non-Alzheimer's dementia, whereas exercise programs were associated with poor cognition [29]. The reason for this could be that the training programs focused on improving lower limb strength, balance, and mobility. de Souto Barreto et al. found that the decreased cognition level in exercise group was greater than that in patients who received music mediation or arts and crafts [31]. Patients recruited in this study were older than those in the other studies, and excess training might contribute additional burden in them, showing declination in cognitive function faster than expected. Subgroup analysis 
TABle 2: Subgroup analyses for cognition, ADL, and depression.

\begin{tabular}{|c|c|c|c|c|c|c|c|}
\hline Outcomes & Factors & Groups & $\begin{array}{l}\text { SMD and } 95 \% \\
\text { CI }\end{array}$ & $\begin{array}{c}P \\
\text { value }\end{array}$ & $\begin{array}{c}\text { Heterogeneity } \\
(\%)\end{array}$ & $\begin{array}{c}P \text { value for } \\
\text { heterogeneity }\end{array}$ & $\begin{array}{c}P \text { value between } \\
\text { subgroups }\end{array}$ \\
\hline \multirow{14}{*}{ Cognition } & \multirow{2}{*}{ Publication year } & $\begin{array}{l}\text { Before } \\
2010\end{array}$ & $\begin{array}{c}-0.03(-0.37 \text { to } \\
0.30)\end{array}$ & 0.845 & 31.4 & 0.224 & 0.366 \\
\hline & & $\begin{array}{l}2010 \text { or } \\
\text { after }\end{array}$ & $\begin{array}{l}0.61(-0.24 \text { to } \\
1.47)\end{array}$ & 0.160 & 97.6 & $<0.001$ & \\
\hline & \multirow{2}{*}{ Country } & Europe & $\begin{array}{c}0.31(-0.47 \text { to } \\
1.08)\end{array}$ & 0.435 & 97.4 & $<0.001$ & 0.001 \\
\hline & & Others & $\begin{array}{c}0.83(-0.28 \text { to } \\
1.93)\end{array}$ & 0.145 & 89.1 & $<0.001$ & \\
\hline & \multirow{2}{*}{ Sample size } & $\geq 100$ & $\begin{array}{c}0.15(-1.18 \text { to } \\
1.48)\end{array}$ & 0.825 & 98.8 & $<0.001$ & 0.286 \\
\hline & & $<100$ & $\begin{array}{l}0.57(-0.06 \text { to } \\
1.21)\end{array}$ & 0.076 & 90.2 & $<0.001$ & \\
\hline & \multirow{2}{*}{ Mean age (years) } & $\geq 80.0$ & $\begin{array}{c}0.09(-0.84 \text { to } \\
1.01)\end{array}$ & 0.854 & 96.1 & $<0.001$ & $<0.001$ \\
\hline & & $<80.0$ & $\begin{array}{c}0.97(0.07 \text { to } \\
1.87)\end{array}$ & 0.035 & 96.6 & $<0.001$ & \\
\hline & \multirow{2}{*}{ Control } & Usual & $\begin{array}{c}1.06(0.35 \text { to } \\
1.76)\end{array}$ & 0.003 & 95.1 & $<0.001$ & $<0.001$ \\
\hline & & Others & $\begin{array}{c}-0.47(-1.56 \text { to } \\
0.61)\end{array}$ & 0.395 & 96.6 & $<0.001$ & \\
\hline & \multirow{2}{*}{$\begin{array}{l}\text { Treatment duration } \\
\text { (months) }\end{array}$} & $\geq 6$ & $\begin{array}{c}0.45(-1.01 \text { to } \\
1.90)\end{array}$ & 0.548 & 98.6 & $<0.001$ & 0.563 \\
\hline & & $<6$ & $\begin{array}{c}0.42(-0.11 \text { to } \\
0.95)\end{array}$ & 0.123 & 88.9 & $<0.001$ & \\
\hline & \multirow{2}{*}{ Study quality } & High & $\begin{array}{c}0.43(-0.51 \text { to } \\
1.38)\end{array}$ & 0.371 & 98.0 & $<0.001$ & 0.006 \\
\hline & & Low & $\begin{array}{c}0.44 \text { ( } 0.06 \text { to } \\
0.83)\end{array}$ & 0.024 & 51.2 & 0.069 & \\
\hline \multirow{14}{*}{$\mathrm{ADL}$} & \multirow{2}{*}{ Publication year } & $\begin{array}{l}\text { Before } \\
2010\end{array}$ & $\begin{array}{c}0.18(-0.18 \text { to } \\
0.54)\end{array}$ & 0.328 & 0.0 & 0.549 & 0.706 \\
\hline & & $\begin{array}{l}2010 \text { or } \\
\text { after }\end{array}$ & $\begin{array}{c}0.59(-0.02 \text { to } \\
1.21)\end{array}$ & 0.060 & 95.9 & $<0.001$ & \\
\hline & \multirow{2}{*}{ Country } & Europe & $\begin{array}{c}0.29(-0.28 \text { to } \\
0.87)\end{array}$ & 0.317 & 95.6 & $<0.001$ & 0.001 \\
\hline & & Others & $\begin{array}{c}1.13(-0.68 \text { to } \\
2.94)\end{array}$ & 0.223 & 92.3 & $<0.001$ & \\
\hline & \multirow{2}{*}{ Sample size } & $\geq 100$ & $\begin{array}{c}0.37(-0.13 \text { to } \\
0.88)\end{array}$ & 0.145 & 94.1 & $<0.001$ & 0.068 \\
\hline & & $<100$ & $\begin{array}{c}0.75(-0.98 \text { to } \\
2.48)\end{array}$ & 0.395 & 96.3 & $<0.001$ & \\
\hline & \multirow{2}{*}{ Mean age (years) } & $\geq 80.0$ & $\begin{array}{c}0.43(-0.44 \text { to } \\
1.31)\end{array}$ & 0.334 & 96.6 & $<0.001$ & 0.023 \\
\hline & & $<80.0$ & $\begin{array}{c}0.57(-0.08 \text { to } \\
1.23)\end{array}$ & 0.088 & 90.7 & $<0.001$ & \\
\hline & \multirow{2}{*}{ Control } & Usual & $\begin{array}{c}0.87 \text { (0.19 to } \\
1.54)\end{array}$ & 0.012 & 92.9 & $<0.001$ & 0.080 \\
\hline & & Others & $\begin{array}{c}0.14(-0.76 \text { to } \\
1.04)\end{array}$ & 0.757 & 96.3 & $<0.001$ & \\
\hline & \multirow{2}{*}{$\begin{array}{l}\text { Treatment duration } \\
\text { (months) }\end{array}$} & $\geq 6$ & $\begin{array}{c}0.97(-0.01 \text { to } \\
1.95)\end{array}$ & 0.053 & 96.5 & $<0.001$ & $<0.001$ \\
\hline & & $<6$ & $\begin{array}{c}0.22(-0.43 \text { to } \\
0.88)\end{array}$ & 0.504 & 93.6 & $<0.001$ & \\
\hline & \multirow{2}{*}{ Study quality } & High & $\begin{array}{c}0.56(-0.04 \text { to } \\
1.15)\end{array}$ & 0.066 & 95.9 & $<0.001$ & 0.681 \\
\hline & & Low & $\begin{array}{c}0.35(-0.16 \text { to } \\
0.86)\end{array}$ & 0.180 & 0.0 & 0.347 & \\
\hline
\end{tabular}


TABLE 2: Continued.

\begin{tabular}{|c|c|c|c|c|c|c|c|}
\hline Outcomes & Factors & Groups & $\begin{array}{l}\text { SMD and } 95 \% \\
\text { CI }\end{array}$ & $\begin{array}{c}P \\
\text { value }\end{array}$ & $\begin{array}{c}\text { Heterogeneity } \\
(\%)\end{array}$ & $\begin{array}{c}P \text { value for } \\
\text { heterogeneity }\end{array}$ & $\begin{array}{c}P \text { value between } \\
\text { subgroups }\end{array}$ \\
\hline \multirow{14}{*}{ Depression } & \multirow{2}{*}{ Publication year } & $\begin{array}{l}\text { Before } \\
2010\end{array}$ & $\begin{array}{c}-0.13(-0.41 \text { to } \\
0.14)\end{array}$ & 0.337 & 0.0 & 0.805 & 0.555 \\
\hline & & $\begin{array}{l}2010 \text { or } \\
\text { after }\end{array}$ & $\begin{array}{c}-0.85(-1.83 \text { to } \\
0.12)\end{array}$ & 0.085 & 94.2 & $<0.001$ & \\
\hline & \multirow{2}{*}{ Country } & Europe & $\begin{array}{c}-0.12(-0.29 \text { to } \\
0.06)\end{array}$ & 0.191 & 0.0 & 0.778 & 0.003 \\
\hline & & Others & $\begin{array}{c}-1.33(-4.07 \text { to } \\
1.41)\end{array}$ & 0.341 & 96.0 & $<0.001$ & \\
\hline & \multirow{2}{*}{ Sample size } & $\geq 100$ & $\begin{array}{c}-0.10(-0.29 \text { to } \\
0.08)\end{array}$ & 0.285 & 0.0 & 0.640 & 0.022 \\
\hline & & $<100$ & $\begin{array}{c}-0.94(-2.40 \text { to } \\
0.52)\end{array}$ & 0.209 & 93.1 & $<0.001$ & \\
\hline & \multirow{2}{*}{ Mean age (years) } & $\geq 80.0$ & $\begin{array}{c}-0.16(-0.37 \text { to } \\
0.05)\end{array}$ & 0.129 & 0.0 & 0.913 & 0.558 \\
\hline & & $<80.0$ & $\begin{array}{c}-1.34(-4.03 \text { to } \\
1.35)\end{array}$ & 0.329 & 97.1 & $<0.001$ & \\
\hline & \multirow{2}{*}{ Control } & Usual & $\begin{array}{c}-0.85(-1.90 \text { to } \\
0.19)\end{array}$ & 0.110 & 94.2 & $<0.001$ & 0.757 \\
\hline & & Others & $\begin{array}{c}-0.17(-0.42 \text { to } \\
0.08)\end{array}$ & 0.186 & 0.0 & 0.773 & \\
\hline & \multirow{2}{*}{$\begin{array}{l}\text { Treatment duration } \\
\text { (months) }\end{array}$} & $\geq 6$ & $\begin{array}{c}-0.18(-0.42 \text { to } \\
0.07)\end{array}$ & 0.159 & 0.0 & 0.823 & 0.797 \\
\hline & & $<6$ & $\begin{array}{c}-0.66(-1.56 \text { to } \\
0.24)\end{array}$ & 0.153 & 91.4 & $<0.001$ & \\
\hline & \multirow{2}{*}{ Study quality } & High & $\begin{array}{c}-0.52(-1.06 \text { to } \\
0.02)\end{array}$ & 0.058 & 88.4 & $<0.001$ & 0.440 \\
\hline & & Low & $\begin{array}{c}0.05(-0.61 \text { to } \\
0.71)\end{array}$ & 0.876 & - & - & \\
\hline
\end{tabular}

\begin{tabular}{|c|c|c|c|}
\hline Study & & $\begin{array}{l}\text { Standardised mean difference } \\
(95 \% \mathrm{CI})\end{array}$ & $\%$ weight \\
\hline Francese & \begin{tabular}{l|l}
$\mathbf{a}$ &, \\
\end{tabular} & $-0.17(-1.36,1.02)$ & 6.7 \\
\hline Rolland & & $0.21(-0.16,0.59)$ & 9.7 \\
\hline Conradsson & & $0.14(-0.18,0.45)$ & 9.9 \\
\hline Venturelli & - & $2.16(1.13,3.18)$ & 7.4 \\
\hline Vreugdenhil & & $3.05(2.13,3.98)$ & 7.8 \\
\hline Yang & & $0.46(-0.10,1.03)$ & 9.2 \\
\hline Toots & - & $1.75(1.41,2.09)$ & 9.8 \\
\hline Hoffmann & & $-0.07(-0.36,0.21)$ & 10.0 \\
\hline Barreto & $\leftarrow$ & $-1.65(-2.13,-1.18)$ & 9.5 \\
\hline Bürge & & $0.23(-0.08,0.54)$ & 9.9 \\
\hline Lamb & & $0.01(-0.20,0.23)$ & 10.1 \\
\hline \multirow[t]{3}{*}{ Overall } & 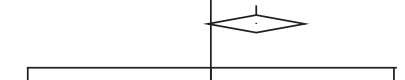 & $\begin{array}{l}0.50(-0.03,1.02) ; P=0.066 \\
(I \text {-square: } 94.9 \% ; P<0.001)\end{array}$ & 100.0 \\
\hline & $\begin{array}{ll}1 & 1 \\
0 & 2\end{array}$ & & \\
\hline & Standardised mean difference & & \\
\hline
\end{tabular}

FIgURE 3: Effect of exercise programs on ADL.

indicated that the treatment effect of exercise programs on cognition level mainly focused on mean age of patients of $<80.0$ years when compared with usual care and pooled low-quality studies. The potential reason for this could be that mean age was correlated with progression of dementia and the control strategy could affect the net treatment effect between exercise program and control. The quality of included studies could affect the evidence level, causing potential biases. The above results suggested that exercise programs were superior to usual care on cognition level, and the strategy of exercise programs should focus on strength and balance. Moreover, exercise 


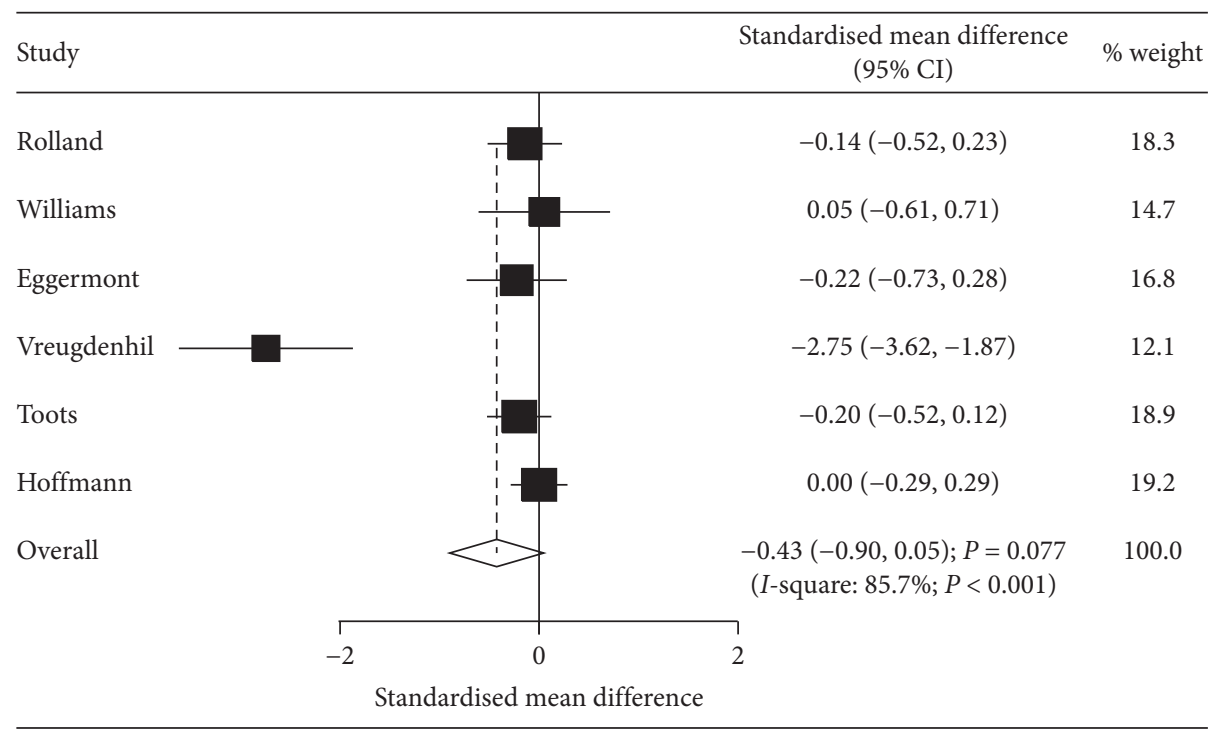

FIGURE 4: Effect of exercise programs on depression.

programs should be given to younger patients with dementia.

Similarly, exercise programs did not yield additional beneficial effects on ADL, whereas a significant difference between exercise programs and control for ADL was observed. Most of the included studies reported no significant differences between exercise programs and control regarding the change in ADL, whereas de Souto Barreto et al. indicated that the levels of ADL in exercise group were lower than those in the control group [31]. Stratified analysis indicated that ADL was significantly improved in patients receiving exercise program when compared with usual care. This significant difference could be due to the fact that the net change between exercise and usual care was larger than the use of other strategies as control. In addition, there was no significant difference between exercise programs and control regarding the levels of depression. This effect was stable and unaltered by sensitivity and subgroup analyses. However, nearly all the included studies reported a positive trend in patients receiving exercise programs, which required further large-scale RCTs to demonstrate the treatment effects of exercise programs on depression.

However, our study has few limitations that should be mentioned. Firstly, the exercise strategy used by the included studies varied, and also the treatment effects of exercise programs differed. Secondly, the levels of cognition, ADL, and depression are evaluated by different scales in different studies, and substantial heterogeneity across the included studies was not fully interpreted. Thirdly, the type of dementia was not assigned in most of the included studies, and the analysis according to the types of dementia was not conducted. Fourthly, the summary results of depression were available in few studies and require verification in further studies. Fifthly, the analysis based on published studies and publication bias was inevitable. Finally, the detailed analysis was not conducted as this study used pooled data due to the unavailability of individual data.

\section{Conclusion}

In conclusion, these results suggested that exercise programs might play a beneficial role in cognition and ADL in patients with dementia, especially in younger patients and when compared with usual care, whereas exercise program showed no association with depression level. These results indicated that exercise programs should be introduced to patients with dementia, especially to younger patients. Further large-scale RCTs should be conducted to verify the treatment effects of exercise program on depression in patients with dementia.

\section{Data Availability}

The datasets used and/or analyzed during the current study are available from the corresponding author on reasonable request.

\section{Conflicts of Interest}

The authors declare that they have no conflicts of interest.

\section{Acknowledgments}

This work was supported by the National Natural Science Foundation (Grant no. 31860598), and the Health Industry Research Project of Gansu Province (Grant no. GSWSKY2017-16).

\section{Supplementary Materials}

Supplement 1: searching strategy in PubMed, Embase, and Cochrane. Supplement 2: it includes 3 figures as follows. Figure S1: sensitivity analysis for cognition. Figure S2: sensitivity analysis for ADL. Figure S3: sensitivity analysis for depression. Supplement 3: it includes 3 figures as follows. Figure S1: funnel plot for cognition. Figure S2: funnel plot 
for ADL. Figure S3: funnel plot for depression. (Supplementary Materials)

\section{References}

[1] K. M. Fiest, N. Jetté, J. I. Roberts et al., "The prevalence and incidence of dementia: a systematic review and meta-analysis," Canadian Journal of Neurological Sciences, vol. 43, no. S1, pp. 3-50, 2016.

[2] Alzheimer's Association, "2015 Alzheimer's disease facts and figures," Alzheimer's Dementia, vol. 11, no. 3, pp. 332-384, 2015.

[3] G. Allali, C. Annweiler, H. M. Blumen et al., "Gait phenotype from mild cognitive impairment to moderate dementia: results from the GOOD initiative," European Journal of Neurology, vol. 23, no. 3, pp. 527-541, 2016.

[4] L. M. Allan, C. G. Ballard, D. J. Burn, and R. A. Kenny, "Prevalence and severity of gait disorders in Alzheimer's and non-Alzheimer's dementias," Journal of the American Geriatrics Society, vol. 53, no. 10, pp. 1681-1687, 2005.

[5] R. Morris, S. Lord, J. Bunce, D. Burn, and L. Rochester, "Gait and cognition: mapping the global and discrete relationships in ageing and neurodegenerative disease," Neuroscience \& Biobehavioral Reviews, vol. 64, pp. 326-345, 2016.

[6] S. Bennett and A. J. Thomas, "Depression and dementia: cause, consequence or coincidence?," Maturitas, vol. 79, no. 2, pp. 184-190, 2014.

[7] C.-C. Tan, J.-T. Yu, H.-F. Wang et al., "Efficacy and safety of donepezil, galantamine, rivastigmine, and memantine for the treatment of Alzheimer's disease: a systematic review and meta-analysis," Journal of Alzheimer's Disease, vol. 41, no. 2, pp. 615-631, 2014.

[8] M. L. Daviglus, C. C. Bell, W. Berrettini et al., "National institutes of health state-of-the-science conference statement: preventing alzheimer disease and cognitive decline," Annals of Internal Medicine, vol. 153, no. 3, pp. 176-181, 2010.

[9] M. J. Marshall and S. A. Hutchinson, "A critique of research on the use of activities with persons with Alzheimer's disease: a systematic literature review," Journal of Advanced Nursing, vol. 35, no. 4, pp. 488-496, 2001.

[10] P. A. Adlard, V. M. Perreau, V. Pop, and C. W. Cotman, "Voluntary exercise decreases amyloid load in a transgenic model of Alzheimer's disease," Journal of Neuroscience, vol. 25, no. 17, pp. 4217-4221, 2005.

[11] C. W. Wu, Y. T. Chang, L. Yu et al., "Exercise enhances the proliferation of neural stem cells and neurite growth and survival of neuronal progenitor cells in dentate gyrus of middle-aged mice," Journal of Applied Physiology, vol. 105, no. 5, pp. 1585-1594, 2008.

[12] D. Forbes, E. J. Thiessen, C. M. Blake, S. S. Forbes, and S. Forbes, "Exercise programs for people with dementia," Sao Paulo Medical Journal, vol. 132, no. 3, pp. 195-196, 2014.

[13] D. Moher, A. Liberati, J. Tetzlaff, D. G. Altman, and The PRISMA Group, "Preferred reporting items for systematic reviews and meta-analyses: the PRISMA statement," PLoS Medicine, vol. 6, no. 7, Article ID e1000097, 2009.

[14] T. Frances, J. Sorrell, and F. R. Butler, "The effects of regularexercise on muscle strength and functional abilities of latestage Alzheimer's residents," American Journal of Alzheimer's Disease, vol. 12, no. 3, pp. 122-127, 1997.

[15] A. Van de Winckel, H. Feys, W. De Weerdt, and R. Dom, "Cognitive and behavioural effects of music-based exercises in patients with dementia," Clinical Rehabilitation, vol. 18, no. 3, pp. 253-260, 2004.
[16] Y. Rolland, F. Pillard, A. Klapouszczak et al., "Exercise program for nursing home residents with Alzheimer's disease: a 1-year randomized, controlled trial," Journal of the American Geriatrics Society, vol. 55, no. 2, pp. 158-165, 2007.

[17] G. Christofoletti, M. M. Oliani, S. Gobbi, F. Stella, L. T. Bucken Gobbi, and P. Renato Canineu, "A controlled clinical trial on the effects of motor intervention on balance and cognition in institutionalized elderly patients with dementia," Clinical Rehabilitation, vol. 22, no. 7, pp. 618-626, 2008.

[18] C. L. Williams and R. M. Tappen, "Exercise training for depressed older adults with Alzheimer's disease," Aging \& Mental Health, vol. 12, no. 1, pp. 72-80, 2008.

[19] L. H. P. Eggermont, D. F. Swaab, E. M. Hol, and E. J. A. Scherder, "Walking the line: a randomised trial on the effects of a short term walking programme on cognition in dementia," Journal of Neurology, Neurosurgery \& Psychiatry, vol. 80, no. 7, pp. 802-804, 2009.

[20] L. H. P. Eggermont, D. L. Knol, E. M. Hol, D. F. Swaab, and E. J. A. Scherder, "Hand motor activity, cognition, mood, and the rest-activity rhythm in dementia: a clustered RCT," Behavioural Brain Research, vol. 196, no. 2, pp. 271-278, 2009.

[21] M. Conradsson, H. Littbrand, N. Lindelöf, Y. Gustafson, and E. Rosendahl, "Effects of a high-intensity functional exercise programme on depressive symptoms and psychological wellbeing among older people living in residential care facilities: a cluster-randomized controlled trial," Aging \& Mental Health, vol. 14, no. 5, pp. 565-576, 2010.

[22] G. Kemoun, M. Thibaud, N. Roumagne et al., "Effects of a physical training programme on cognitive function and walking efficiency in elderly persons with dementia," Dementia and Geriatric Cognitive Disorders, vol. 29, no. 2, pp. 109-114, 2010.

[23] H. H. Hwang and Y. J. Choi, "The effects of the dance therapyprogram through rhythmic exercise on cognitive memoryperformance of the elderly with dementia," in Proceedings of the 21st Pan-Asian Congress of Sports and Physical Education, vol. 4, pp. 12-17, Nanchang, China, April 2010.

[24] M. Venturelli, R. Scarsini, and F. Schena, "Six-month walking program changes cognitive and ADL performance in patients with Alzheimer," American Journal of Alzheimer's Disease \& Other Dementiasr, vol. 26, no. 5, pp. 381-388, 2011.

[25] A. Vreugdenhil, J. Cannell, A. Davies, and G. Razay, “A community-based exercise programme to improve functional ability in people with Alzheimer's disease: a randomized controlled trial," Scandinavian Journal of Caring Sciences, vol. 26, no. 1, pp. 12-19, 2012.

[26] K. M. Volkers, "Physical (in)activity an cognition in cognitivelyimpaired older people: the effect of regular walks oncognition in older people with mild to severe cognitiveimpairment: a long-term randomized controlled trial," $\mathrm{Ph}$. D. dissertation, Vrije University, Amsterdam, Netherlands, 2012.

[27] S.-Y. Yang, C.-L. Shan, H. Qing et al., "The effects of aerobic exercise on cognitive function of Alzheimer's disease patients," CNS \& Neurological Disorders-Drug Targets, vol. 14, no. 10, pp. 1292-1297, 2015.

[28] H. Öhman, N. Savikko, T. E. Strandberg et al., "Effects of exercise on cognition: the Finnish Alzheimer disease exercise trial: a randomized, controlled trial," Journal of the American Geriatrics Society, vol. 64, no. 4, pp. 731-738, 2016.

[29] A. Toots, H. Littbrand, N. Lindelöf et al., "Effects of a highintensity functional exercise program on dependence in activities of daily living and balance in older adults with 
dementia," Journal of the American Geriatrics Society, vol. 64, no. 1, pp. 55-64, 2016.

[30] V. A. Holthoff, K. Marschner, M. Scharf et al., "Effects of physical activity training in patients with Alzheimer's dementia: results of a pilot RCT study," PLoS One, vol. 10, no. 4, Article ID e0121478, 2015.

[31] P. de Souto Barreto, M. Cesari, P. Denormandie, D. Armaingaud, B. Vellas, and Y. Rolland, "Exercise or social intervention for nursing home residents with dementia: a pilot randomized, controlled trial," Journal of the American Geriatrics Society, vol. 65, no. 9, pp. E123-e129, 2017.

[32] E. Bürge, A. Berchtold, C. Maupetit et al., "Does physical exercise improve ADL capacities in people over 65 years with moderate or severe dementia hospitalized in an acute psychiatric setting? a multisite randomized clinical trial," International Psychogeriatrics, vol. 29, no. 2, pp. 323-332, 2017.

[33] S. E. Lamb, B. Sheehan, N. Atherton et al., "Dementia and physical activity (DAPA) trial of moderate to high intensity exercise training for people with dementia: randomised controlled trial,” BMJ, vol. 361, p. k1675, 2018.

[34] A. R. Jadad, R. A. Moore, D. Carroll et al., "Assessing the quality of reports of randomized clinical trials: is blinding necessary?," Controlled Clinical Trials, vol. 17, no. 1, pp. 1-12, 1996.

[35] R. DerSimonian and N. Laird, "Meta-analysis in clinical trials," Controlled Clinical Trials, vol. 7, no. 3, pp. 177-188, 1986.

[36] A. E. Ades, G. Lu, and J. P. T. Higgins, "The interpretation of random-effects meta-analysis in decision models," Medical Decision Making, vol. 25, no. 6, pp. 646-654, 2005.

[37] J. J. Deeks, J. P. T. Higgins, and D. G. Altman, "Analyzing data and undertaking meta-analyses," in Cochrane Handbook for Systematic Reviews of Interventions 501, J. Higgins and G. Se, Eds., The Cochrane Collaboration, Oxford, UK, 2008.

[38] J. P. T. Higgins, S. G. Thompson, J. J. Deeks, and D. G. Altman, "Measuring inconsistency in meta-analyses," BMJ, vol. 327, no. 7414, pp. 557-560, 2003.

[39] A. Tobias, "Assessing the influence of a single study in metaanalysis," Stata Technical Bulletin, vol. 8, no. 47, pp. 15-17, 1999.

[40] S. G. Thompson and J. P. T. Higgins, "How should metaregression analyses be undertaken and interpreted?, Statistics in Medicine, vol. 21, no. 11, pp. 1559-1573, 2002.

[41] M. Egger, G. D. Smith, M. Schneider, and C. Minder, "Bias in meta-analysis detected by a simple, graphical test," $B M J$, vol. 315, no. 7109, pp. 629-634, 1997.

[42] C. B. Begg and M. Mazumdar, "Operating characteristics of a rank correlation test for publication bias," Biometrics, vol. 50, no. 4, pp. 1088-1101, 1994.

[43] Z. Du, Y. Li, J. Li, C. Zhou, F. Li, and X. Yang, "Physical activity can improve cognition in patients with Alzheimer's disease: a systematic review and meta-analysis of randomized controlled trials," Clinical Interventions in Aging, vol. 13, pp. 1593-1603, 2018.

[44] C. G. Blankevoort, M. J. G. van Heuvelen, F. Boersma, H. Luning, J. de Jong, and E. J. A. Scherder, "Review of effects of physical activity on strength, balance, mobility and ADL performance in elderly subjects with dementia," Dementia and Geriatric Cognitive Disorders, vol. 30, no. 5, pp. 392-402, 2010.

[45] H. S. Lee, S. W. Park, and Y. J. Park, "Effects of physical activity programs on the improvement of dementia symptom: a meta-analysis," BioMed Research International, vol. 2016, Article ID 2920146, 7 pages, 2016.
[46] J.-H. Liang, Y. Xu, L. Lin, R.-X. Jia, H.-B. Zhang, and L. Hang, "Comparison of multiple interventions for older adults with Alzheimer disease or mild cognitive impairment: a PRISMAcompliant network meta-analysis," Medicine, vol. 97, no. 20, Article ID e10744, 2018. 


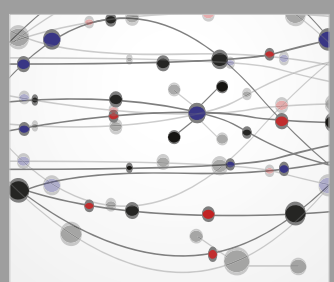

The Scientific World Journal
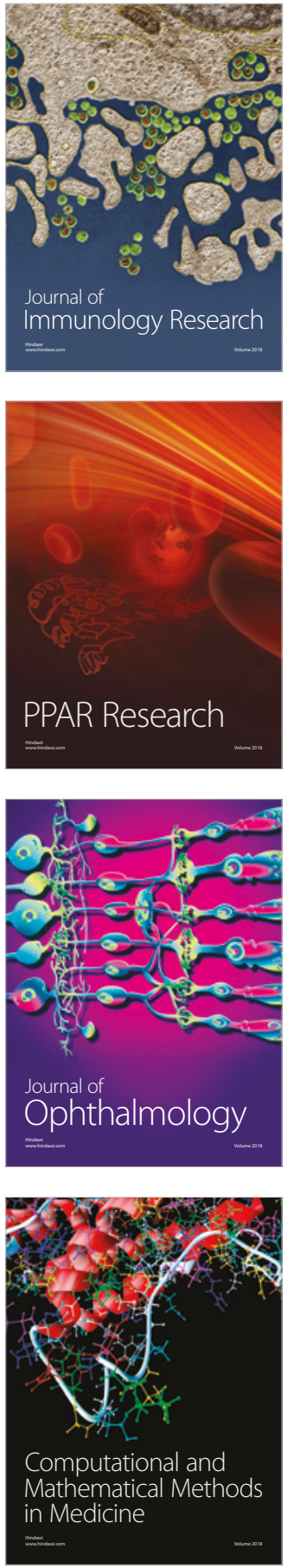

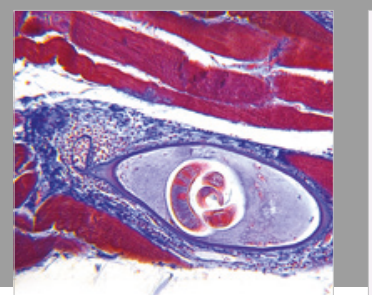

Gastroenterology Research and Practice

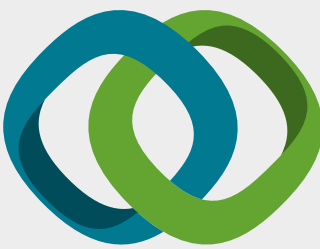

\section{Hindawi}

Submit your manuscripts at

www.hindawi.com
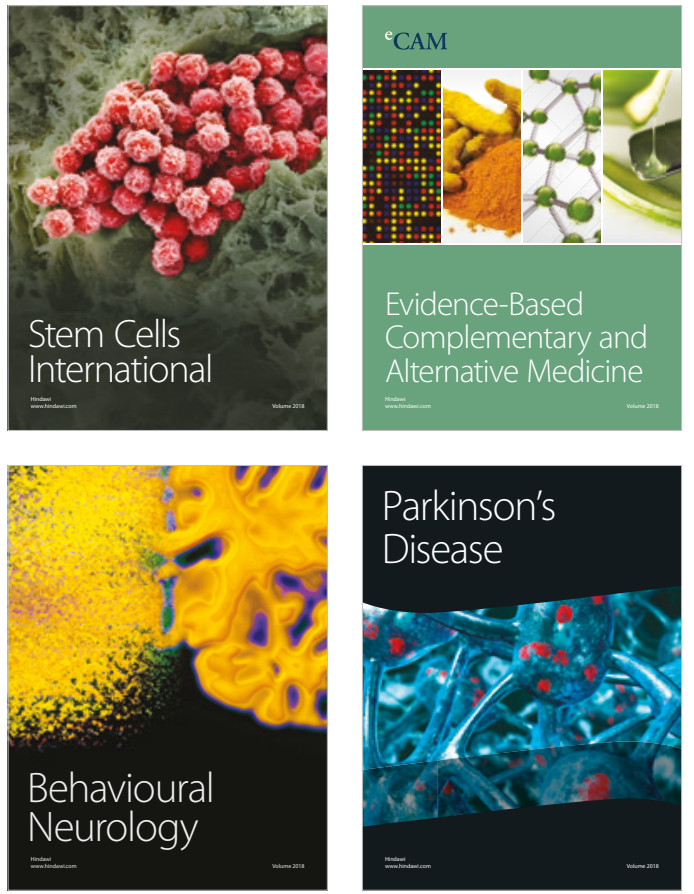

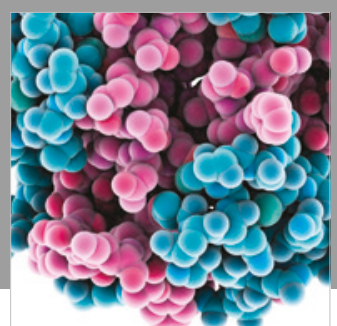

ournal of

Diabetes Research

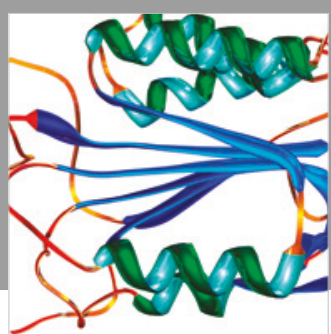

Disease Markers
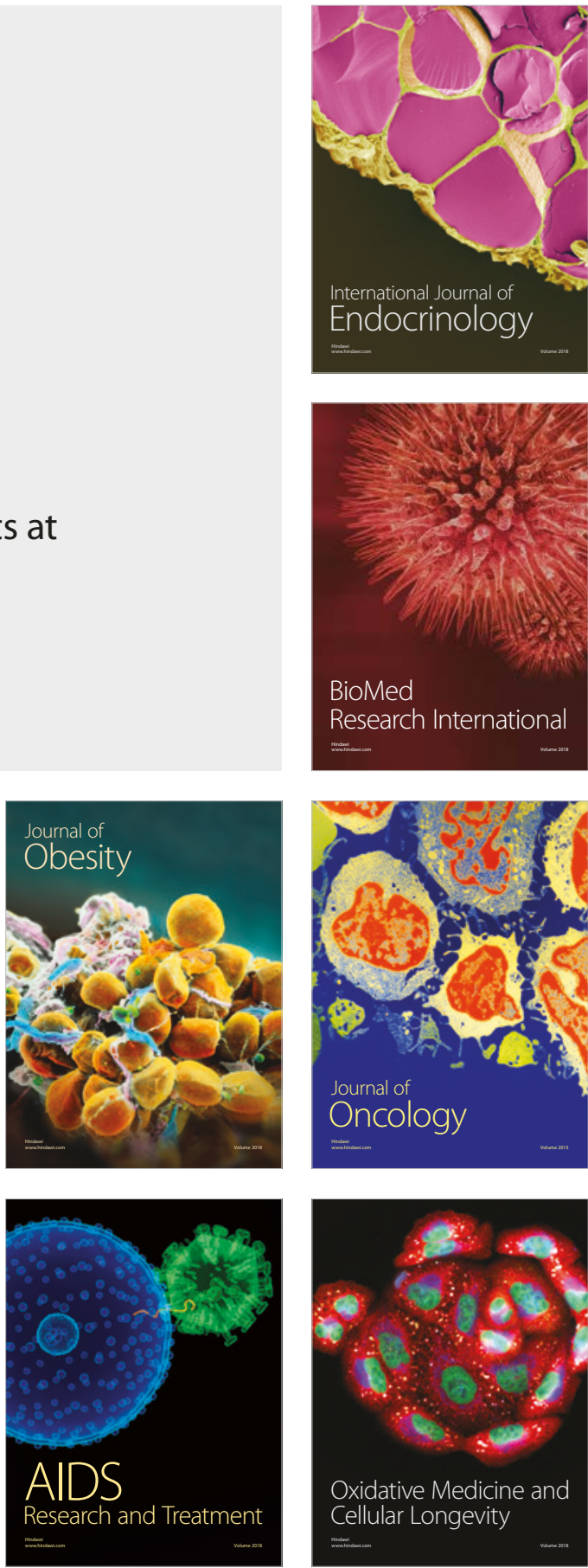